\title{
Closed Cell Aluminium Foams with Phase Change Material
}

\author{
Jaroslav KOVÁČIK*, Ján ŠPANIELKA, Tomáš DVORÁK, Peter Oslanec Jr., Jaroslav \\ JERZ
}

Institute of Materials and Machine Mechanics SAS, Dúbravská cesta 9, 84513 Bratislava, Slovakia e-mail: ummsjk@savba.sk,ummsspan@savba.sk,ummsdvor@savba.sk,ummsoslo@savba.sk, ummsjerz@savba.sk

*corresponding author

Keywords: metallic foams, aluminium foams, phase change materials, zero energy buildings, heat dissipation

\begin{abstract}
Closed cell aluminium foam samples and panels with phase change material (PCM) infiltrated in vacuum were investigated. The utilization of PCMs in larger volumes is strongly limited because of its low thermal conductivity in liquid state. However, porous structure of aluminium foam allows to absorb or to dissipate very homogenously latent heat at almost constant temperature if PCMs with phase change at the temperature range between $4^{\circ} \mathrm{C}$ and $28{ }^{\circ} \mathrm{C}$ are used inside of foam. Therefore the degree of filling of closed cell aluminium foams with PCM material was investigated. It was shown that it is possible to fill sufficient amount of pores with PCM. Further, aluminium foam panels with PCM were tested for heating/cooling applications in buildings. It was confirmed, that such foam panels provide an excellent alternative for large built-in ceiling radiators for efficient heating or cooling of rooms using low potential energy resources. These features of foam panels allow significantly reduce energy consumption of heating/air conditioning systems of future zero energy buildings.
\end{abstract}

\section{Introduction}

The most convenient way how to decrease energy demands in the buildings is the utilization of renewable energy sources - the solar, wind or geothermal one [1-4]. The main drawbacks of them are irregularity of output power and localization of some sources to certain places. That is why it is important to focus on development of new systems which will be able to cover these natural energy fall-outs by storing and subsequent later evolving the accumulated heat or cold according to the day-night cycle.

The thermal energy is stored in standard buildings usually into massive inserts (i.e. clay bricks), but the sensible heat can be stored also if the Phase Change Materials (PCMs) are used for thermal energy storage [2]. Their most important property is the solid-liquid phase change and vice versa at the temperature range between $4^{\circ} \mathrm{C}$ and $28^{\circ} \mathrm{C}$ [5]. During this change, all latent heat is evolved or absorbed at almost constant temperature.

The utilization of PCMs in larger volumes is strongly limited because of its low thermal conductivity in liquid state. In this case solidification starts on the surface creating thus an isolating 
solid crust. That is a reason why there is a need to combine PCMs and porous materials with higher thermal conductivity. Guo et al. [6] showed that paraffin/ graphite foam composite can be considered as suitable candidates for latent heat thermal energy storage device. Large effort has been recently done on open cell metallic foams (copper, aluminium) [7-14]. The phase change behaviour of paraffin saturated in porous foams has been intensively investigated by experimental and numerical approaches. The metal foams exploited for enhancing phase change heat transfer are mainly made by ERG Corporation (open porosity foams), whose foam struts are solid due to the direct foaming fabrication routine, but the foam structure is open celled. Little concern has been paid to closed cell metallic foams. Therefore, the aim of this article is to investigate the possibility to fill closed cell aluminium foams (prepared by powder metallurgical route) with PCM material. Further, the effort will be given on heating/cooling properties of such composite material.

\section{Experimental procedure}

Experimental works were done on closed aluminium foam samples (Fig. 1) prepared via powder metallurgical route by foaming in special ovens at $700^{\circ} \mathrm{C}$ [15]. The composition of used aluminium alloy was AlSi10 alloy. Typical density of aluminium foam panels were around 0.65 g. $\mathrm{cm}^{-3}$. Panel geometry is $330 \times 330 \mathrm{~mm}$ with variable thickness due to foamed in steel tube ( $18 \times 370 \mathrm{~mm}$, thickness $1 \mathrm{~mm}$ ), which supplies heat to the panel or removes it from the panel. For X-ray micro tomography cylindrical samples with diameter of $55 \mathrm{~mm}$ and length of $50 \mathrm{~mm}$ were used. Typical density of cylindrical samples was $0.76 \mathrm{~g} \cdot \mathrm{cm}^{-3}$.
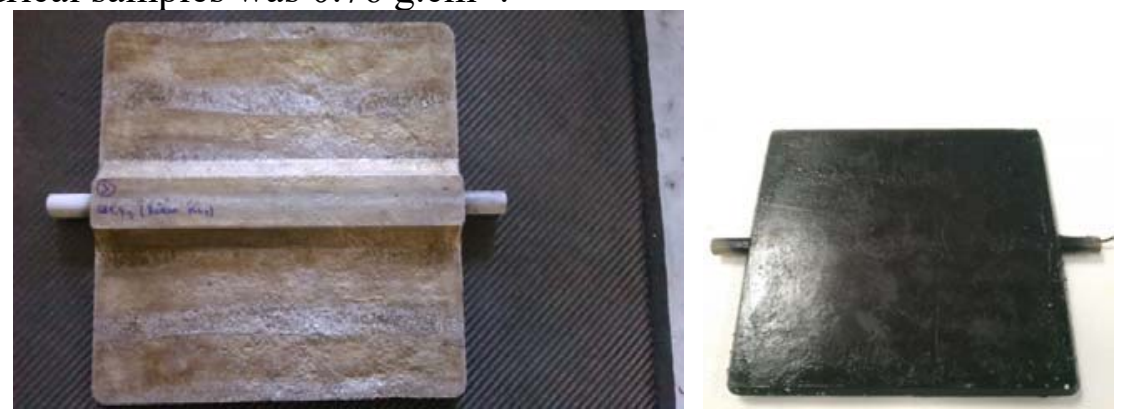

Figure. 1 Experimental heating/cooling aluminium foam plate and its lower surface waterproof coated (black colour) infiltrated with PCM.

The prepared samples were then experimentally waterproof coated on reverse side to prevent leakage of the molten PCM material. After that the panel was infiltrated with PCM in the vacuum chamber as follows: Material Rubitherm RT28HC or RT27 [5] has been heated in a heating vessel chamber up to $40{ }^{\circ} \mathrm{C}$ while aluminium foam panels were heated parallel in external furnace up to $45{ }^{\circ} \mathrm{C}$. After the desired temperatures have been reached in both, foam panel was transferred to vacuum chamber, which was closed and evacuated to a vacuum of $10-20 \mathrm{kPa}$. Subsequently, the melted PCM material was poured onto the surface of the foam panel and, after covering the entire surface of the panel and stabilization of PCM level, the chamber was pressurised. The difference of pressure between the surroundings and the interior of aluminium foam secured PCM infiltration into the evacuated pores. After cooling down of the infiltrated foam panel below $25{ }^{\circ} \mathrm{C}$ (below solidification temperature of PCM) the panel can be easily handled. The same technology with small changes due to sample size was used for cylindrical samples.

To measure the ability to store heat as well as to determine the amount of heat irradiated from panel the special device was constructed - see Fig. 2. It consists of PVC foam chamber $400 \mathrm{x} 400 \mathrm{x}$ $1000 \mathrm{~mm}$ on top of which is mounted prepared aluminium foam plate, which is also isolated using closed-cell PVC foam. For heating/cooling of the inner cavity the foam sample is connected to laboratory thermostat and heated up to $40{ }^{\circ} \mathrm{C}$ using technically clean water as heating/cooling medium. Then the flow of water is stopped and heating/cooling performance is measured. 
Temperature measurement is done using thermocouples in aluminium foam plate (TC1 - see Fig.2) and also in the centre of bottom part of empty cavity (TC2).

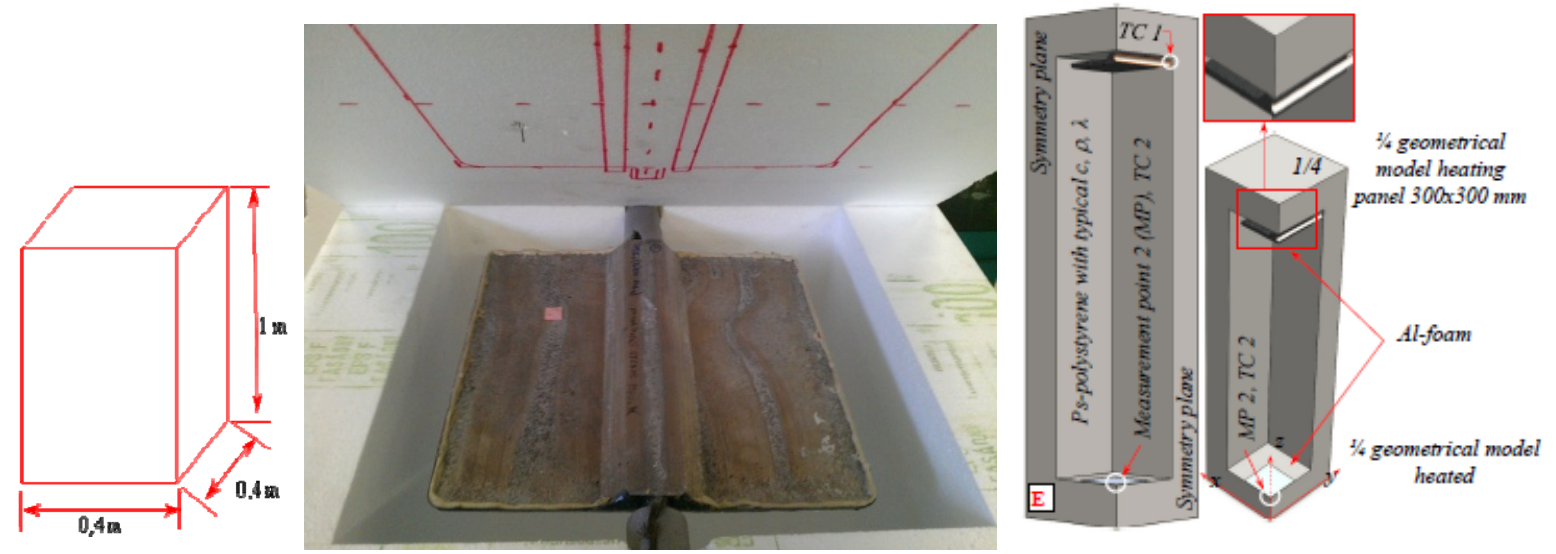

Figure. 2 Experimental equipment (left) for measuring heating/cooling performance of aluminium foam plate (middle) with/without PCM and usual placement of measuring thermocouples TC1 and TC2.

For the evaluation of the degree of infiltration/quality of infiltration of aluminium foam plate with PCM material X-ray micro tomography Phoenix Nanotom, USA for non destructive analysis of the internal structure of materials was used.

\section{Results and discussion}

X-ray micro tomography (Fig. 3) confirmed that the infiltration of PCM was almost perfect. It is thanks to the presence of the small cracks inside of pore walls. These cracks are the result of aluminium foam production route - cracking of very thin pore walls occurs during solidification of foam due to solidification shrinkage of metal alloy, the cell wall thinning due to local drainage and rupture of cell walls because of pore gas inner pressure differences [16]. This confirms assumption about interconnectivity of aluminium foam pores. However, as indicates Fig. 3 there are still some pores, which are not infiltrated with PCM at all. This is probably partially caused by the closed porosity in aluminium foam and partially due to local variations of flow of liquid PCM during infiltration.

Software included in X-ray micro tomography Phoenix Nanotom enables to estimate the volume of infiltrated PCM and residual porosity in aluminium foam plate. It was observed that the piece of aluminium foam plate used for X-ray tomography has typical porosity of $69 \%$. It was infiltrated with PCM which fills in solid state 57 vol. \%. The rest of the volume, i.e., 12 vol. \% is residual porosity. It is not as bad as it seems because the producer of PCM states that during melting/solidification used PCM changes its volume by $10 \%$. Using this data infiltrated PCM fills in liquid state 63 vol. \% and only 6 vol. \% is residual closed porosity.

The experimental results obtained in special measuring device showed that thanks to good conductivity of aluminium foam the heating of the panel is almost immediate and is only slowly postponed due to the melting of amount of infiltrated PCM (Figs. 4 and 5) - dynamic regime. In static cooling regime, due to energy stored in PCM the cooling cycle is significantly different. The amount of stored heat energy in infiltrated PCM depends significantly on the weight of PCM in foam plate. In cooling it is slowly released from infiltrated into the foam panel by subsequent solidification/melting of the PCM volumes in pores. This confirms significant improvement for stabilisation of the room temperatures in buildings when using PCM infiltrated aluminium foams plates. 
It can be concluded that the considerable disadvantage of PCMs used for heat storage - their extremely low thermal conductivity (RT28HC thermal conductivity is around $0.2 \mathrm{~W} / \mathrm{m} . \mathrm{K}$ [5]) can be solved successfully using metallic foams with thermal conductivity of metal skeleton in the range from 76 to $235 \mathrm{~W} / \mathrm{m}$.K (according to used aluminium alloy). However further optimization with respect to pore size, interconnectivity between pores, type of used aluminium alloy, amount of $\mathrm{PCM}$, etc. is necessary.
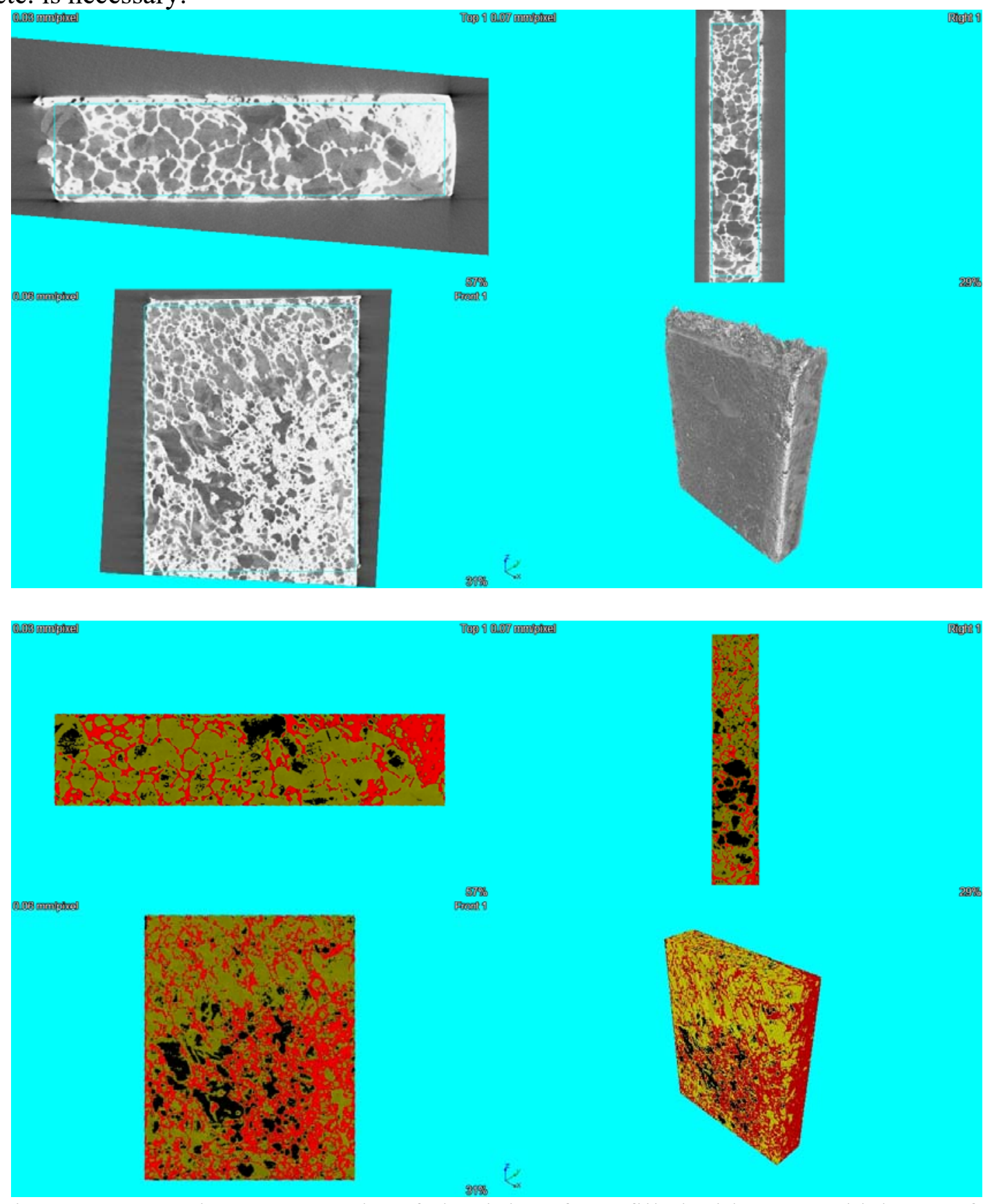

Figure.3 X-ray micro tomography of aluminium foam filled with PCM. Thickness of sample is $15 \mathrm{~mm}$, - average pore size of $3.5 \mathrm{~mm}$, top - reconstructed 3D structure, bottom - detection of PCM and porosity: red - aluminium foam, yellow - PCM, black - porosity. 


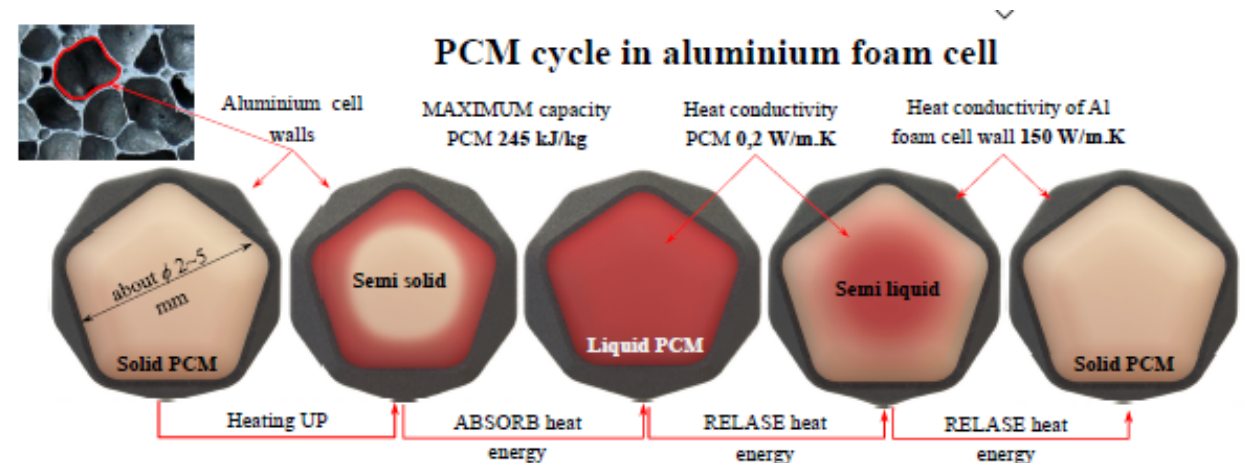

Figure. 4 Schematic description of heating/cooling performance of aluminium foam plate infiltrated with PCM.

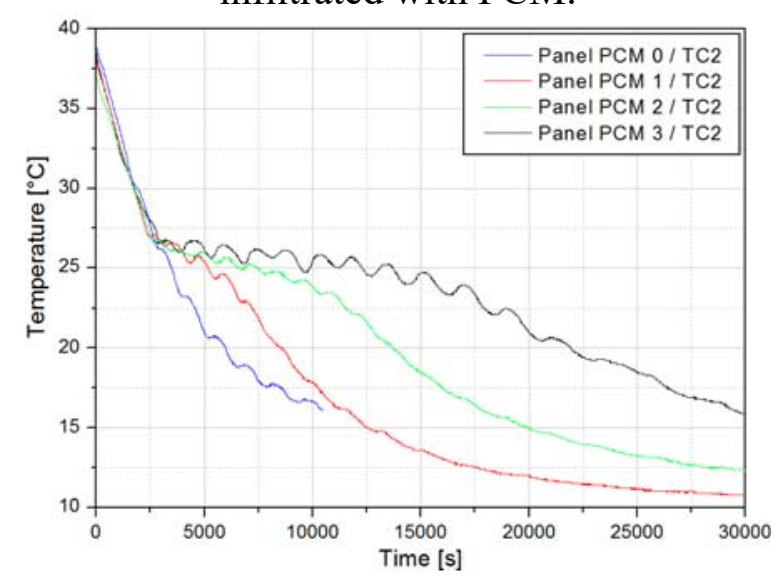

Figure. 5 Measured heating/cooling performance of aluminium foam plate with different amount of PCM: $0-$ zero, $1-100 \mathrm{~g}, 2-200 \mathrm{~g}$ and $3-300 \mathrm{~g}$ of PCM.

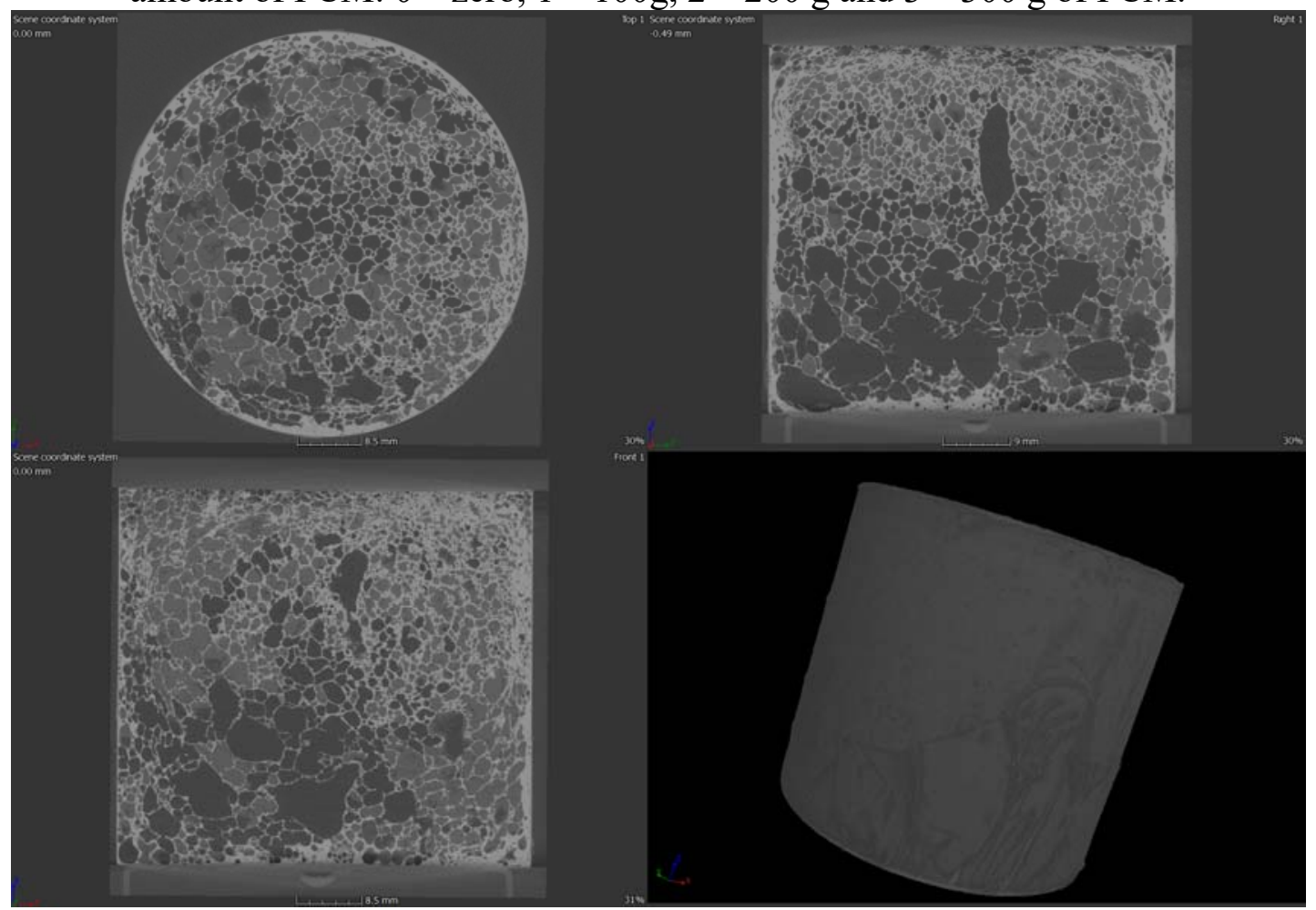

Figure. 6 RTG picture of closed cell aluminium foam sample infiltrated with PCM (solid PCM). Foam density 0.75 g. $\mathrm{cm}^{-3}, 40 \mathrm{~g}$ of infiltrated PCM, room temperature. 


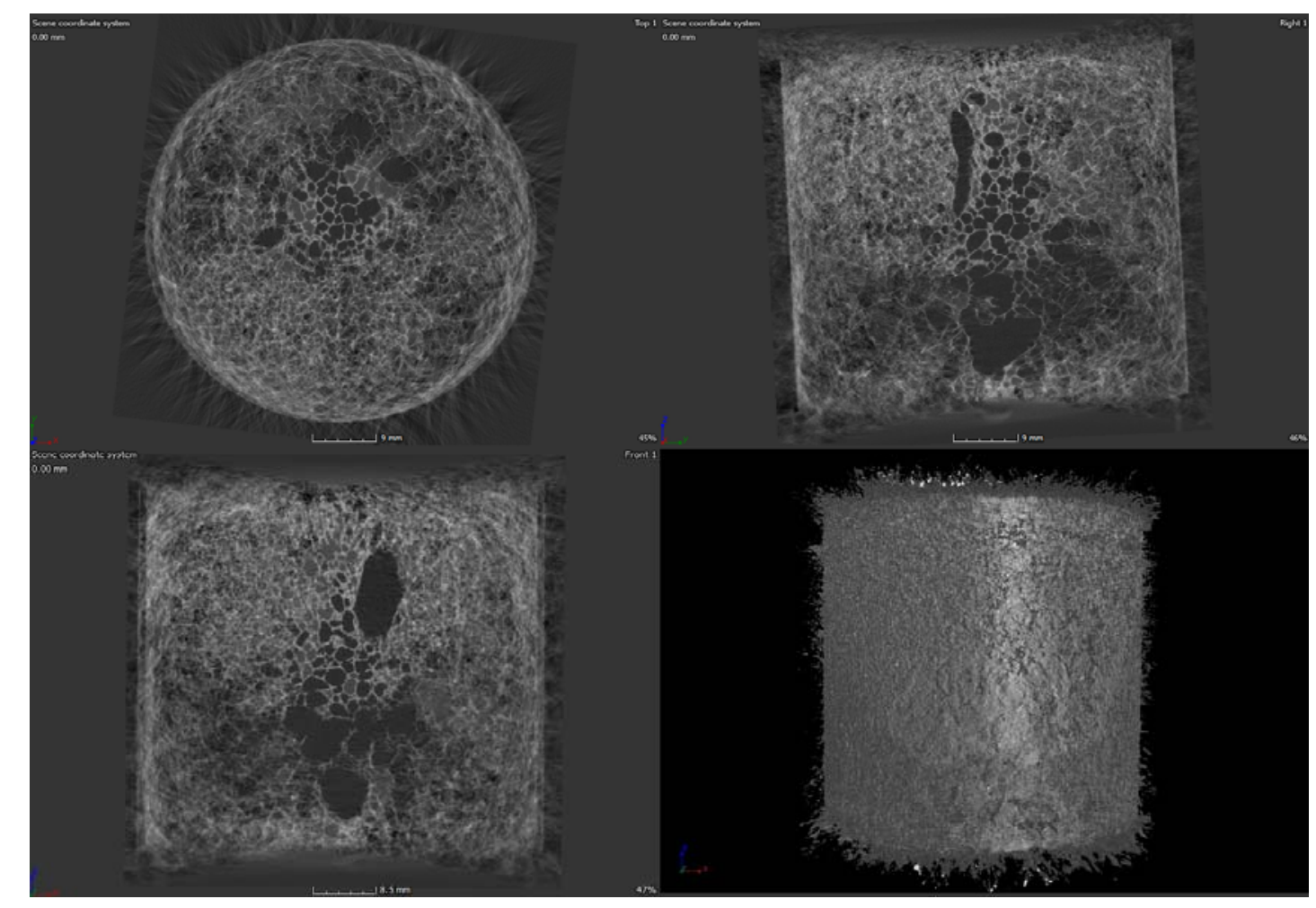

Figure. 7 RTG picture of closed cell aluminium foam sample infiltrated with PCM (liquid PCM). Foam density $0.75 \mathrm{~g} . \mathrm{cm}^{-3}, 40 \mathrm{~g}$ of infiltrated PCM, temperature $35^{\circ} \mathrm{C}$.

Finally PCM position in cylindrical aluminium foam sample was observed after infiltration at room temperature (PCM in solid state) and subsequently at $35^{\circ} \mathrm{C}$ (PCM in liquid state) - above PCM phase transition temperature using X-ray micro tomography. Unfortunately, the movement of foam sample inside X-ray micro tomograph causes inevitable "ghost" effects on resulting 3D reconstructed pictures due to motion of liquid PCM inside of foam pores (see Figs. 6 and 7 for comparison). It can be concluded that at present-day level of X-ray technology it is difficult to observe liquid PCM in moving closed cell aluminium foam. Remark: the observations were done on foam samples infiltrated with PCM under not optimised conditions, therefore large vol. \% of porosity without PCM can be observed.

\section{Conclusions}

Closed cell aluminium foam prepared by powder metallurgical route was successfully infiltrated with PCM material.

RTG tomography of closed cell aluminium foam showed that the cracks in pore walls enables fairy well to infiltrate also closed cell aluminium foams with liquid PCM. It was observed that in the case of foam with $70 \%$ porosity above $80 \%$ of porosity can be successfully filled with liquid PCM, some residual porosity remains due to volumetric changes of PCM during phase transition (shrinking during solidification).

It was further showed that the movement of foam sample inside X-ray micro tomograph causes inevitable "ghost" effects on resulting 3D reconstructed pictures due to motion of liquid PCM inside of foam pores when sample temperature is above phase transition temperature of PCM. Thus the direct observation of liquid PCM in foam structure is biased with liquid PCM motions.

A new type of heating/cooling system based on aluminium foam plates $330 \mathrm{x} 330 \mathrm{~mm}$ infiltrated with PCM materials with water as cooling/heating medium was prepared and 
investigated for various amount of PCM. It was confirmed that PCM infiltration improved heating/cooling properties of this system. The developed closed cell aluminium foam panels provide an excellent alternative for large built-in ceiling radiators for efficient heating or cooling of rooms using low potential energy resources.

The main reason is that the disadvantage of PCMs used for heat storage - their extremely low thermal conductivity can be solved successfully using metallic foams with thermal conductivity of metal skeleton. However further optimization with respect to pore size, interconnectivity between foam pores, type of used aluminium alloy, amount of used PCM, etc. is necessary.

\section{Acknowledgement}

The financial support from the Slovak R\&D Agency (project: Heating/cooling panel based on aluminium foam filled by PCM, APVV-0692-12) and VEGA agency projects 2/0044/17, 2/0065/16, 2/0152/17 are gratefully acknowledged.

\section{References}

[1] Jerz J., Simančík F., Orovčík L., Advanced solution for energy storage in net zero-energy buildings. In Mechanical Technologies and Structural Materials 2014. - Split: Croatian Society for Mechanical Technologies, (2014) 47-54.

[2] de Boer R., Smeding S., Zondag H. and Krol G., Development of a prototype system for seasonal solar heat storage using an open sorption process, In Eurotherm Seminar \#99, Advances in Thermal Energy Storage, (2014), Lleida, Spain.

[3] Jerz J., Tobolka, P., Michenka, V. and Dvorák, T., Heat storage in future zero-energy buildings. In International Journal of Innovative Research in Science, Engineering and Technology, (2015), vol. 4, iss. 8, 6722-6728, DOI:10.15680/IJIRSET.2015.0408003.

[4] Jerz J., Simančík F., Kováčik, J., Oslanec, P., Sr., Energy demand reduction to ensure thermal comfort in buildings using aluminium foam. In Acta Metallurgica Slovaca, 2016, 22, č. 4, s. 271-275. ISSN 1338-1156.

[5] RUBITHERM PCM RT28HT Data sheet, Rubitherm Technologies GmbH, Berlin, Germany, 2014.

[6] C X Guo, X L Ma, L Yang, PCM/ graphite foam composite for thermal energy storage device, 2015 Global Conference on Polymer and Composite Materials (PCM 2015), IOP Publishing, IOP Conf. Series: Materials Science and Engineering 87 (2015) 012014 doi:10.1088/1757-899X/87/1/012014

[7] X. Yang, W. Wang, S. Feng, L. Jun, T.J. Lu, Y. Chai, Q. Zhang Thermal analysis of cold storage: the role of porous metal form, Energy Procedia, 88 (2016), pp. 566-573

[8] C.Y. Zhao, W. Lu, Y. Tian, Heat transfer enhancement for thermal energy storage using metal foams embedded within phase change materials (PCMs)Sol Energy, 84 (2010), pp. 1402-1412

[9] X. Xiao, P. Zhang, M. Li, Preparation and thermal characterization of paraffin/metal foam composite phase change material, Appl Energy, 112 (2013), pp. 1357-1366

[10] S.S. Feng, Y. Zhang, M. Shi, T. Wen, T.J. Lu, Unidirectional freezing of phase change materials saturated in open-cell metal foams, Appl Therm Eng, 88 (2015), pp. 315-321

[11] A. Siahpush, J. O’Brien, J. Crepeau, Phase change heat transfer enhancement using copper porous foam, J Heat Transf, 130 (2008), p. 082301

[12] E. Fleming, S.Y. Wen, L. Shi, A.K. Silva, Experimental and theoretical analysis of an aluminum foam enhanced phase change thermal storage unit, Int J Heat Mass Transf, 82 (2015), pp. 273-281

[13] O. Mesalhy, K. Lafdi, A. Elgafy, K. Bowman, Numerical study for enhancing the thermal conductivity of phase change material (PCM) storage using high thermal conductivity porous matrix, Energy Conver Manag, 46 (2005), pp. 847-867

[14] X.H. Yang, J.X. Bai, H.B. Yan, J.J. Kuang, T. Kim, T.J. Lu, An analytical unit cell model for the effective thermal conductivity of high porosity open-cell metal foams, Trans Porous Med, 102 (2014), pp. 403-426

[15] Kováčik, J., Orovčík, L., Jerz, J., High-temperature compression of closed cell aluminium foams. In Kovove Mater, 2016, Vol 54, No. 6, pp. 429-440. ISSN 0023-432X

[16] Lazaro, J.; Solórzano, E.; Rodriguez Pérez, M.A.; Garcia-Moreno, F.: Pore connectivity of aluminium foams: effect of production parameters. Journal of Materials Science 50 (2015), p. 3149-3163 